\title{
Investigation of a Photoelectrochemical Passivated ZnO-Based Glucose Biosensor
}

\section{Ching-Ting Lee ${ }^{1{ }^{*}}$, Ying-Shuo Chiu ${ }^{1}$, Shu-Ching Ho ${ }^{2}$ and Yao-Jung Lee ${ }^{2}$}

1 Institute of Microelectronics, Department of Electrical Engineering, National Cheng Kung University, 701, Tainan, Taiwan; E-Mail: q18991120@mail.ncku.edu.tw (Y.-S.C.)

2 Microsystems Technology Center, Industrial Technology Research Institute, Tainan, Taiwan; E-Mails: itri990067@itri.org.tw (S.-C.H.); yjlee@itri.org.tw (Y.-J.L.)

* Author to whom correspondence should be addressed; E-Mail: ctlee@ee.ncku.edu.tw; Tel.: +886-6-2082368; Fax: +886-6-2082368.

Received: 22 February 2011; in revised form: 27 March 2011 / Accepted: 22 April 2011 / Published: 28 April 2011

\begin{abstract}
A vapor cooling condensation system was used to deposit high quality intrinsic $\mathrm{ZnO}$ thin films and intrinsic $\mathrm{ZnO}$ nanorods as the sensing membrane of extended-gate field-effect-transistor (EGFET) glucose biosensors. The sensing sensitivity of the resulting glucose biosensors operated in the linear range was $13.4 \mu \mathrm{A} \mathrm{mM}^{-1} \mathrm{~cm}^{-2}$. To improve the sensing sensitivity of the $\mathrm{ZnO}$-based glucose biosensors, the photoelectrochemical method was utilized to passivate the sidewall surfaces of the $\mathrm{ZnO}$ nanorods. The sensing sensitivity of the $\mathrm{ZnO}$-based glucose biosensors with passivated $\mathrm{ZnO}$ nanorods was significantly improved to $20.33 \mu \mathrm{A} \mathrm{mM} \mathrm{mm}^{-1}$ under the same measurement conditions. The experimental results verified that the sensing sensitivity improvement was the result of the mitigation of the Fermi level pinning effect caused by the dangling bonds and the surface states induced on the sidewall surface of the $\mathrm{ZnO}$ nanorods.
\end{abstract}

Keywords: extended-gate field-effect-transistors; photoelectrochemical method; vapor cooling condensation technique; $\mathrm{ZnO}$-based glucose biosensors; $\mathrm{ZnO}$ nanorods 


\section{Introduction}

Recently, there has been great concern about health issues due to the irregular living and diet habits of humans. Diabetes mellitus is one of the main causes of death and disability. It can cause heart disease, kidney nephropathy, and blindness. Glucose biosensors, which possess high sensitivity, low-cost, reliable characteristics for biomedical measurement, have become key instruments in blood glucose monitors, biological analyses, chemical analyses, and clinical detection. Field-effect-transistor (FET) -based devices have been widely used in biosensors [1,2]. Among the FET-based biosensors, the extended-gate field-effect-transistor (EGFET) is a promising device thanks to its easier fabrication process [3]. The extended-gate field-effect-transistors consist of two parts, including the sensing membrane structure and the metal-oxide-semiconductor field-effect-transistor (MOSFET) structure. With its isolated electrical and sensing parts, the MOSFET does not need to be in contact with the solutions during the biosensor measurement process. Moreover, the extended-gate sensing electrode is less influenced by the optical illumination and the operation temperature. Besides, it can be disposable. Therefore, biosensors of EGFET structure can be applied in fast, convenient and low cost medical tests.

In view of its high stability and selectivity to glucose, glucose oxidase (GOD) has been widely utilized in glucose biosensors, especially the amperometric glucose biosensors [4]. To establish a friendly environment for immobilizing the enzyme, the sensing membrane of glucose sensors has to be selected appropriately. $\mathrm{ZnO}$ is a promising membrane material due to its wide bandgap (3.3 eV), stability, non toxicity, and ideal biocompatible properties. Furthermore, because the isoelectric point (IEP) of $\mathrm{ZnO}$ is about 9.5, the $\mathrm{ZnO}$ is suitable for adsorption of low IEP proteins or enzyme [5]. In view of these advantages of high specific surface area, good biological compatibility and stability, $\mathrm{ZnO}$ nanorods have been attracted intense attention and have been used in various biosensors [3,5-7]. Although several methods have been developed to deposit ZnO-based materials onto various substrates [8-11], the high quality and high resistivity intrinsic $\mathrm{ZnO}$ film and intrinsic $\mathrm{ZnO}$ nanorods required in glucose biosensors are difficult to obtain, because the $\mathrm{ZnO}$ usually exhibits n-type conductivity behavior owing to the compensation effect induced by the oxygen vacancies and the zinc interstitials $[12,13]$. Recently, a novel vapor cooling condensation system was built to deposit high quality $\mathrm{ZnO}$ films and $\mathrm{ZnO}$ nanorods [14,15]. In this work, in order to fabricate the sensing membrane part of the EGFETs, $\mathrm{ZnO}$ films and nanorods were deposited using this vapor cooling condensation system. However, a Fermi level pinning effect is induced by the existence of a lot of dangling bonds and surface states located on the sidewall surface of the $\mathrm{ZnO}$ nanorods. Consequently, the band alignment of the electrolyte/semiconductor junction cannot be effectively changed with the various $\mathrm{pH}$ values of the measuring solution. Therefore, the sensing performance of the glucose biosensors is seriously degraded. In this work, to circumvent this drawback, the sidewall surface of the $\mathrm{ZnO}$ nonorods was passivated using the photoelectrochemical (PEC) method. Consequently, the influence of the Fermi level pinning effect can be mitigated owing to the reduction of the dangling bonds and the surface states. 


\section{Experimental Process}

To fabricate the glucose biosensor EGFETs, a 100-nm-thick Al layer was first deposited on a silicon ( $\mathrm{Si}$ ) substrate as the conducing layer. A 200-nm-thick intrinsic $\mathrm{ZnO}$ film and an 80-nm-long intrinsic $\mathrm{ZnO}$ nanorod array were then deposited on the $\mathrm{Al}$ conducting layer using the vapor cooling condensation system. A schematic configuration of the $\mathrm{ZnO}$ glucose biosensors is shown in Figure 1.

Figure 1. The schematic configuration of $\mathrm{ZnO}$ nanorod glucose biosensors.

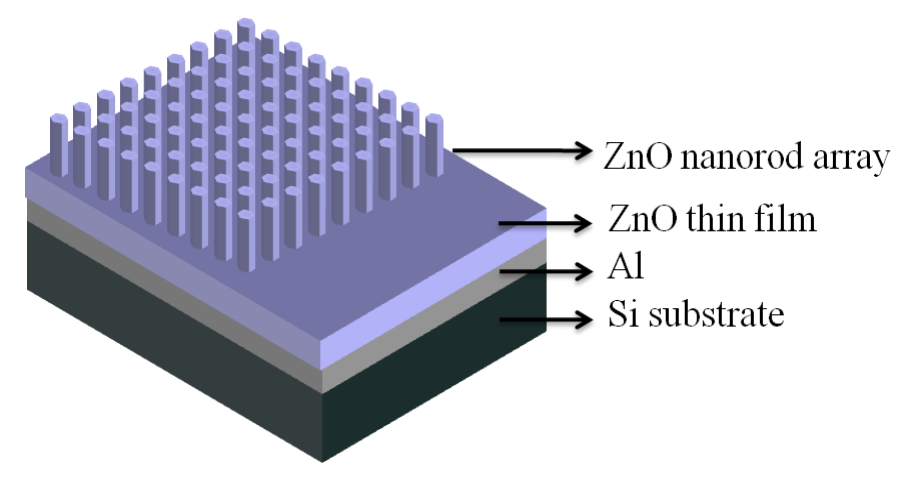

The electron concentration and electron mobility of the deposited intrinsic $\mathrm{ZnO}$ films were $2.3 \times 10^{15} \mathrm{~cm}^{-3}$ and $3.1 \mathrm{~cm} / \mathrm{V}$-sec, respectively. For depositing the nanorod array, an anodic alumina membrane (AAM) template was intimately covered with the deposited intrinsic $\mathrm{ZnO}$ film. The pore diameter and pore density of the AAM template were $100 \mathrm{~nm}$ and $5 \times 10^{9} \mathrm{~cm}^{-2}$, respectively. During the deposition of the intrinsic $\mathrm{ZnO}$ film and nanorod array, the Si substrate was attached on a liquid nitrogen-cooled stainless steel plate. The sublimated $\mathrm{ZnO}$ vapor materials originated from the heated $\mathrm{ZnO}$ powder (purity $=99.99 \%$ ) loaded in a tungsten boat were then cooled and condensed on the Si substrate. To passivate the dangling bonds and the surface states induced on the sidewall surface of the intrinsic $\mathrm{ZnO}$ nanorods using the photoelectrochemical method, a thin $\mathrm{Zn}(\mathrm{OH})_{2}$ layer was directly grown in an ammonia $\left(\mathrm{NH}_{3}\right)$ chemical solution $(\mathrm{pH}$ value $=8)$ under the illumination of a He-Cd laser (power density $=10.0 \mathrm{~mW} / \mathrm{cm}^{2}$ and wavelength $=325 \mathrm{~nm}$ ). This photoelectrochemical system was reported previously [16,17]. The reactions taking place in the photoelectrochemical process can be described as follows:

$$
\begin{gathered}
\mathrm{NH}_{3}+\mathrm{H}_{2} \mathrm{O} \rightarrow \mathrm{NH}_{4}{ }^{+}+\mathrm{OH}^{-} \\
\mathrm{Zn}+2 \mathrm{~h}^{+}+2 \mathrm{OH}^{-} \rightarrow \mathrm{Zn}(\mathrm{OH})_{2}
\end{gathered}
$$

where $\mathrm{h}^{+}$represents the holes optically generated by the illumination with the He-Cd laser. A thin $\mathrm{Zn}(\mathrm{OH})_{2}$ layer was formed on the sidewall surface of the intrinsic $\mathrm{ZnO}$ nanorods and passivated the dangling bonds and the surface states. To fabricate the glucose biosensors, the sensing membrane of the EGFETs was encapsulated with an epoxy resin and only the exposed active sensing region was left. Furthermore, for fabricating the enzyme immobilization layer, a 3-glycidyloxypropyltrimethoxysilane (GPTS) and toluene mixture was spun on the sensing membrane. After baking at $120{ }^{\circ} \mathrm{C}$ for two hours, the biosensor was immersed in a phosphate buffer solution (PBS) $(5 \mathrm{mM}, \mathrm{pH}=7)$ to wash away the unbounded GPTS. After the mixture solution of GOD (100 U/mg) and $5 \mathrm{mM}$ phosphate buffer solution 
( $\mathrm{pH}$ value of 7.4) was dropped onto the enzyme immobilization layer, the biosensor was shielded from light and kept at $4{ }^{\circ} \mathrm{C}$ for $24 \mathrm{~h}$.

\section{Experimental Results and Discussion}

\subsection{Measurement System}

To measure the $\mathrm{pH}$ sensing characteristics of the glucose biosensors, the biosensor and a $\mathrm{Ag} / \mathrm{AgCl}$ reference electrode were dipped into the buffer solution (the $\mathrm{pH}$ value varied from 4 to 12 ) and the $\mathrm{Al}$ conducting layer was connected to the gate of the commercial MOSFET device (CD4007). An Agilent 4156C Semiconductor Parameter Analyzer was used to measure the drain-source current of the MOSFET device. The measuring system is shown in Figure 2.

Figure 2. The measurement system of $\mathrm{ZnO}$ nanorod glucose biosensors.

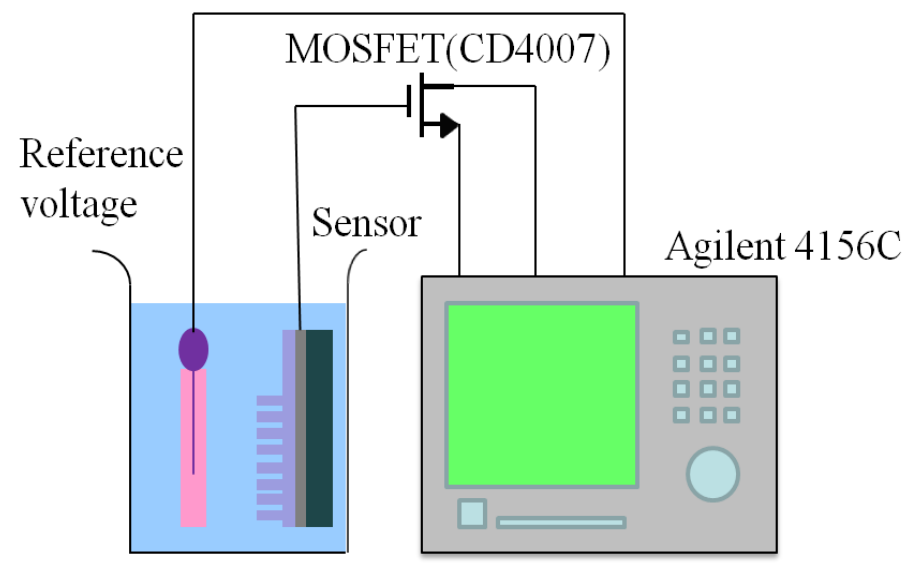

\section{2. pH Sensing Characteristic}

The dependence of the drain-source current $\left(\mathrm{I}_{\mathrm{DS}}\right)$ on the drain-source voltage $\left(\mathrm{V}_{\mathrm{DS}}\right)$ of the glucose biosensors with unpassivated $\mathrm{ZnO}$ nanorods and with passivated $\mathrm{ZnO}$ nanorods operated at a reference electrode voltage $\left(\mathrm{V}_{\mathrm{REF}}\right)$ of $3 \mathrm{~V}$ is shown in Figure 3(a,b), respectively.

Figure 3. Drain-source current-drain-source voltage characteristics of the glucose biosensors with (a) unpassivated $\mathrm{ZnO}$ nanorod, and (b) passivated $\mathrm{ZnO}$ nanorod.
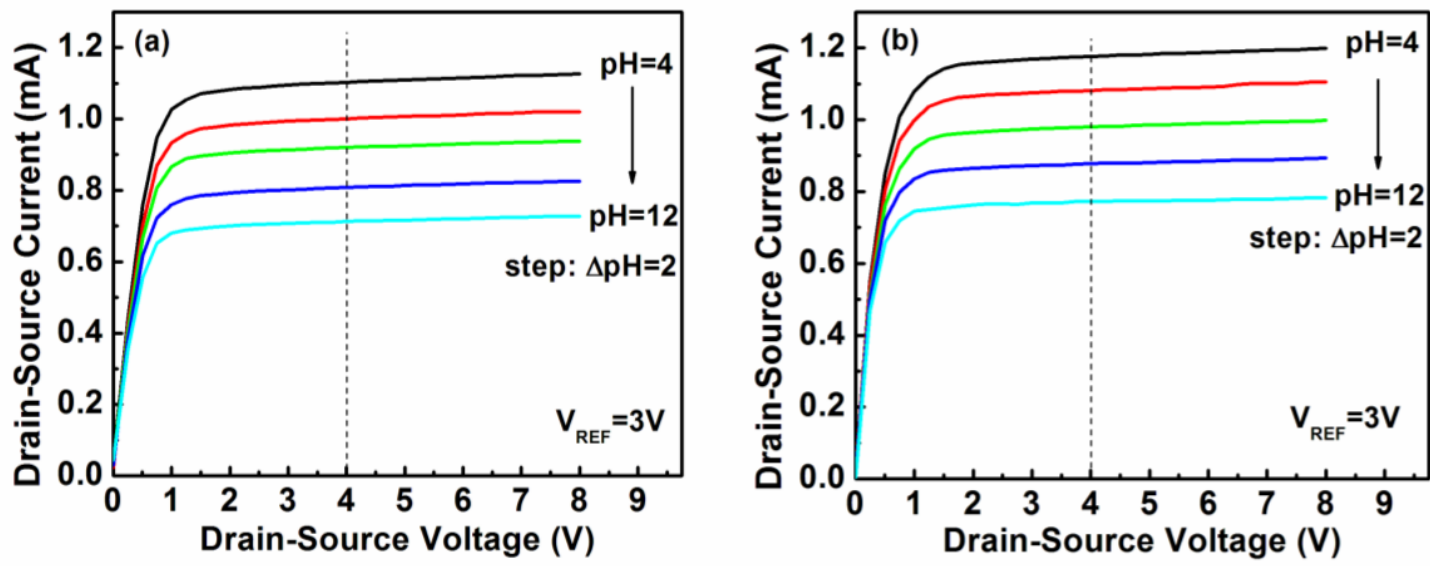
Based on the experimental results shown in Figure 3(a,b), the measured drain-source current as a function of the $\mathrm{pH}$ value of the two kinds of biosensors is shown in Figure 4, where the drain-source voltage $\left(\mathrm{V}_{\mathrm{DS}}\right)$ of the MOSFET operated at $4 \mathrm{~V}$ and the reference electrode voltage $\left(\mathrm{V}_{\mathrm{REF}}\right)$ was $3 \mathrm{~V}$. The $\mathrm{pH}$ sensitivity shown in Figure 4 was calculated from the linear relation between the drain-source current and the $\mathrm{pH}$ value of the two kinds of biosensors. The sensing sensitivity of the glucose biosensors with unpassivated and passivated $\mathrm{ZnO}$ nanorods was $47.96 \mu \mathrm{A} / \mathrm{pH}$ and $52.58 \mu \mathrm{A} / \mathrm{pH}$, respectively. It could thus be seen that the passivation of the nanorods improved the sensing sensitivity of the glucose biosensors. This experimental result verified that the glucose biosensors with PEC passivation treatment have better sensing performances due to the reduction of Fermi level pinning effect caused by the dangling bonds and the surface states.

Figure 4. Drain-source current as a function of $\mathrm{pH}$ value.

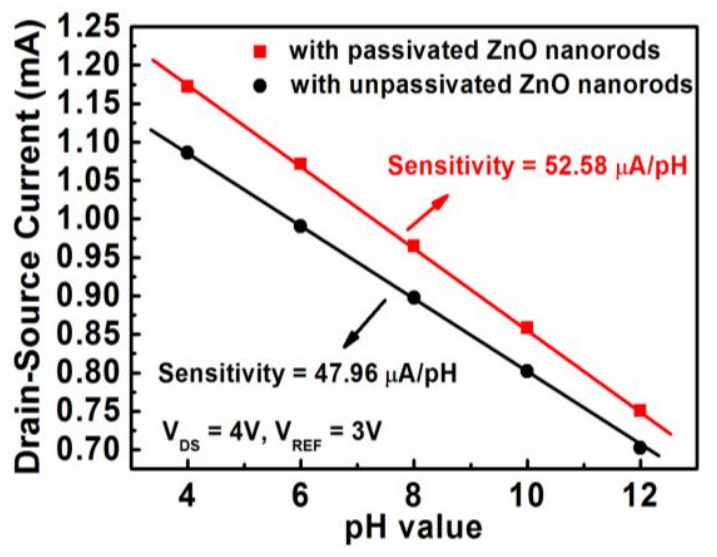

\subsection{The Sensing Characteristics of Glucose Biosensors}

The mechanism of electrochemical glucose biosensors is based on an enzymatic reaction catalyzed by GOD according to the following reaction [18]:

$$
\begin{gathered}
\beta \text {-D-glucose }+\mathrm{O}_{2} \stackrel{\mathrm{GOD}}{\rightarrow} \text { D-glucono- } \delta \text {-lactone }+\mathrm{H}_{2} \mathrm{O}_{2} \\
\qquad 2 \mathrm{H}_{2} \mathrm{O}_{2} \rightarrow 2 \mathrm{H}_{2} \mathrm{O}+\mathrm{O}_{2} \\
\text { D-glucono- } \delta \text {-lactone }+\mathrm{H}_{2} \mathrm{O} \rightarrow \text { D-gluconate }+\mathrm{H}^{+}
\end{gathered}
$$

In the reaction of Equation (3), the $\beta$-D-glucose was catalyzed by the glucose oxidase to produce hydrogen peroxide and D-glucono- $\delta$-lactone. The hydrogen peroxide was then spontaneously converted to $\mathrm{H}_{2} \mathrm{O}$ and oxygen as indicated in Equation (4). The oxygen was further reused in the reaction of glucose catalyzing. Finally, the D-glucono- $\delta$-lactone was hydrolyzed to gluconic acid and produced hydrogen ions $\left(\mathrm{H}^{+}\right)$as shown in the reaction of Equation (5). The production of hydrogen ions reduced the $\mathrm{pH}$ value of the medium. Consequently, the glucose concentration could be determined by the change of $\mathrm{pH}$ value. To measure the sensing sensitivity and the response speed, the glucose biosensor was immersed in $1 \mathrm{mM}$ phosphate buffer solution (PBS) $(\mathrm{pH}=7.5)$ and the glucose concentration gradually increased in $0.5 \mathrm{mM}$ steps. Figure $5(\mathrm{a}, \mathrm{b})$ show the drain-source current response of the unpassivated and the passivated $\mathrm{ZnO}$ nanorod glucose biosensors operated at a drainsource voltage $\left(\mathrm{V}_{\mathrm{DS}}\right)$ of $4 \mathrm{~V}$ and a reference electrode voltage $\left(\mathrm{V}_{\mathrm{REF}}\right)$ of $3 \mathrm{~V}$, respectively. 
Figure 5. Drain-source current response of (a) the unpassivated $\mathrm{ZnO}$ nanorod glucose biosensors and (b) the passivated $\mathrm{ZnO}$ nanorod glucose biosensors.
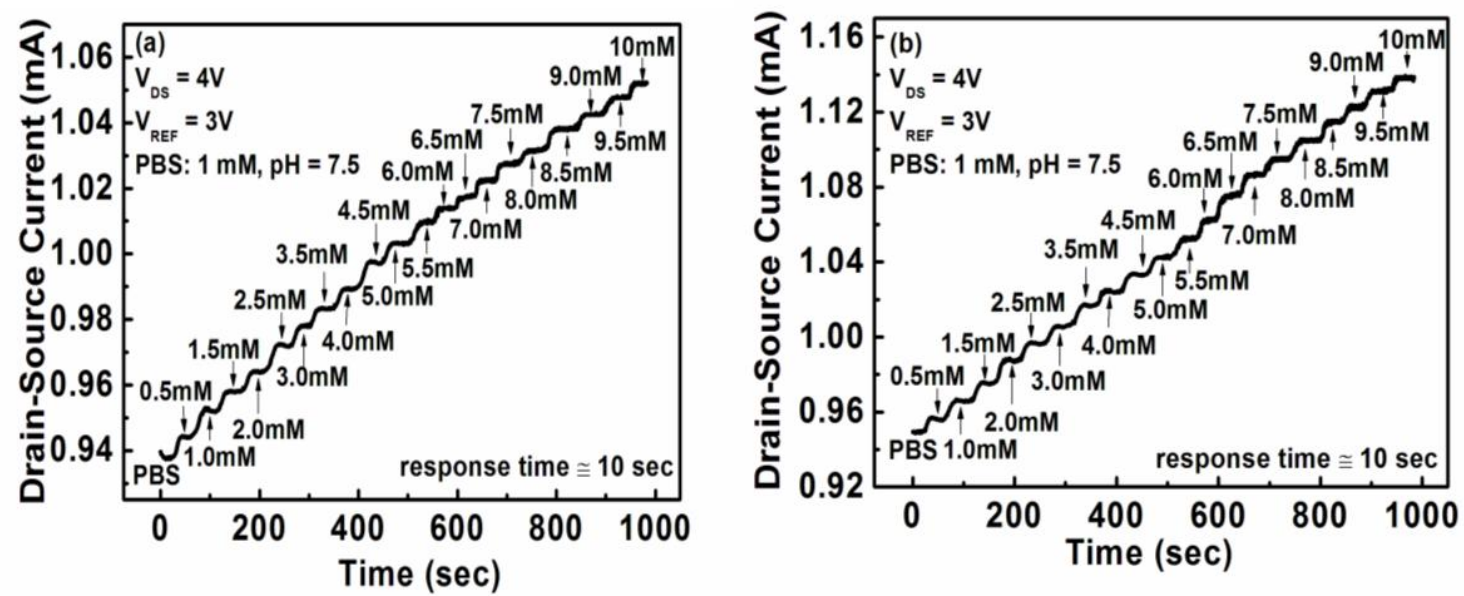

Based on the experimental results shown in Figure 5(a,b), the drain-source current change as a function of the glucose concentration is shown in Figure 6. The drain-source current change was referred the associated current measured in PBS solution. Both the unpassivated and the passivated $\mathrm{ZnO}$ nanorod glucose biosensors exhibited linear sensing sensitivity at a lower glucose concentration and then were prone to gradual saturation at a higher glucose concentration. The response time was about $10 \mathrm{~s}$. The linear sensing sensitivity of the unpassivated and the passivated $\mathrm{ZnO}$ nanorod glucose biosensors was $13.4 \mu \mathrm{A} \mathrm{mM} \mathrm{cm}^{-2}$ and $20.33 \mu \mathrm{A} \mathrm{mM}^{-1} \mathrm{~cm}^{-2}$, respectively.

Figure 6. Drain-source current change as a function of glucose concentration of the unpassivated and the passivated glucose biosensors.

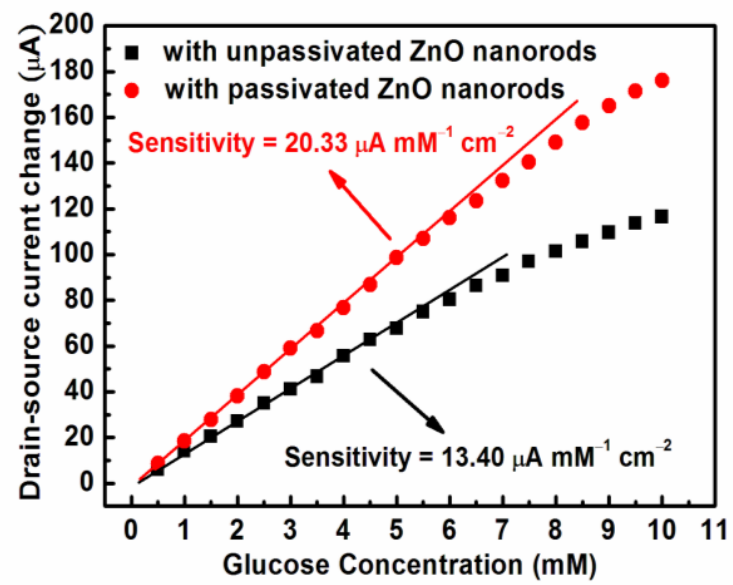

\section{Conclusions}

In this work, a vapor cooling condensation system was successfully utilized to deposit the high quality intrinsic $\mathrm{ZnO}$ film and nanorods required for the fabrication of EGFETs in glucose biosensors. A sensing sensitivity of $13.4 \mu \mathrm{A} \mathrm{mM} \mathrm{mm}^{-1} \mathrm{~cm}^{-2}$ was obtained with the resulting glucose biosensors. To improve the sensing performance, a photoelectrochemical method was used to passivate the dangling bonds and the surface states located at the sidewall surface of the $\mathrm{ZnO}$ nanorods The Fermi level 
pinning effect was thus diminished by the passivation and the sensitivity of the passivated $\mathrm{ZnO}$ nanorod glucose biosensors was improved to $20.33 \mu \mathrm{A} \mathrm{mM} \mathrm{mm}^{-1} \mathrm{~cm}^{-2}$. These promising $\mathrm{ZnO}$-based biosensors can be expected to be applied in biomedical instruments by using the developed vapor cooling condensation system and the photoelectrochemical method.

\section{Acknowledgements}

This work was supported by the National Science Council, Taiwan, under the 99-2221-E-006-208MY3.

\section{References}

1. Chi, L.L.; Chou, J.C.; Chung, W.Y.; Sun, T.P.; Hsiung, S.K. Study on extended gate field effect transistor with tin oxide sensing membrane. Mater. Chem. Phys. 2000, 63, 19-23.

2. Kang, B.S.; Wang, H.T.; Ren, F.; Pearton, S.J.; Morey, T.E.; Dennis, D.M.; Johnson, J.W.; Rajagopal, P.; Roberts, J.C.; Piner, E.L.; Linthicum, K.J. Enzymatic glucose detection using ZnO nanorods on the gate region of $\mathrm{AlGaN} / \mathrm{GaN}$ high electron mobility transistors. Appl. Phys. Lett. 2007, 91, 252103:1-252103:3.

3. Muhammad, S.; Ali, U.; Nur, O.; Willander, M.; Danielsson, B. Glucose detection with a commercial MOSFET using a $\mathrm{ZnO}$ nanowires extended gate. IEEE Trans. Nanotechnol. 2009, 8, 678-683.

4. Kong, T.; Chen, Y.; Ye, Y.; Zhang, K.; Wang, Z.X.; Wang, X.P. An amperometric glucose biosensor based on the immobilization of glucose oxidase on the $\mathrm{ZnO}$ nanotubes. Sens. Actuat. $B$ 2009, 138, 344-350.

5. Zhang, F.F.; Wang, X.L.; Ai, S.Y.; Sun, Z.D.; Wan, Q.; Zhu, Z.Q.; Xian, Y.Z.; Jin, L.T.; Yamamoto, K. Immobilization of uricase on $\mathrm{ZnO}$ nanorods for a reagentless uric acid biosensor. Anal. Chim. Acta 2004, 519, 155-160.

6. Wei, A.; Sun, X.W.; Wang, J.X.; Lei, Y.; Cai, X.P.; Li, C.M.; Dong, Z.L.; Huang, W. Enzymatic glucose biosensor based on $\mathrm{ZnO}$ nanorod array grown by hydrothermal decomposition. Appl. Phys. Lett. 2006, 89, 123902:1-123902:3.

7. Al-Hilli, S.M.; Öst, A.; Strålfors, P.; Willander, M. ZnO nanorods as an intracellular sensor for pH measurements. J. Appl. Phys. 2007, 102, 187-200.

8. Lee, C.T.; Yu, Q.X.; Tang, B.T.; Lee, H.Y.; Hwang, F.T. Investigation of indium tin oxide/zinc oxide multilayer ohmic contacts to n-type GaN isotype conjunction. Appl. Phys. Lett. 2001, 78, 3412-3414.

9. Eisermann, S.; Sann, J.; Polity, A.; Meyer, B.K. Sputter deposition of ZnO thin films at high substrate temperatures. Thin Solid Films 2009, 517, 5805-5807.

10. Lai, L.W.; Lee, C.T. Investigation of optical and electrical properties of $\mathrm{ZnO}$ thin films. Mater. Chem. Phys. 2008, 110, 393-396.

11. Sierros, K.A.; Banerjee, D.A.; Morris, J.N.; Cairns, D.R.; Kortidis, I.; Kiriakidis, G. Mechanical properties of $\mathrm{ZnO}$ thin films deposited on polyester substrates used in flexible device applications. Thin Solid Films 2010, 519, 325-330. 
12. Lai, L.W.; Yan, J.T.; Chen, C.H.; Lou, L.R.; Lee, C.T. Nitrogen function of aluminum-nitride codoped $\mathrm{ZnO}$ films deposited using cosputter system. J. Mater. Res. 2009, 24, 2252-2258.

13. Look, D.C.; Hemsky, J.W.; Sizelove, J.R. Residual native shallow donor in ZnO. Phys. Rev. Lett. 1999, 82, 2552-2555.

14. Chung, R.W.; Wu, R.X.; Lai, L.W.; Lee, C.T. ZnO-on-GaN heterojunction light-emitting diode grown by vapor cooling condensation technique. Appl. Phys. Lett. 2007, 91, 231113:1-23113:3.

15. Lee, C.T.; Lin, Y.H.; Lai, L.W.; Lou, L.R. Mechanism investigation of p-i-n ZnO-based light-emitting diodes. IEEE Photon. Technol. Lett. 2010, 22, 30-32.

16. Lee, H.Y.; Huang, X.Y.; Lee, C.T. Light output enhancement of GaN-based roughened LEDs using bias-assisted photoelectrochemical etching method. J. Electrochem. Soc. 2008, 155, H707-H709.

17. Tseng, C.Y.; Lee, C.S.; Shin, H.Y.; Lee, C.T. Investigation of surface passivation on GaAs-based compound solar cell using photoelectrochemical oxidation method. J. Electrochem. Soc. 2010, 157, H779-H782.

18. Luo, X.L.; Xu, J.J.; Zhao, W.; Chen, H.Y. A novel glucose ENFET based on the special reactivity of $\mathrm{MnO}_{2}$ nanoparticles. Biosens. Bioelectron. 2004, 19, 1295-1300.

(C) 2011 by the authors; licensee MDPI, Basel, Switzerland. This article is an open access article distributed under the terms and conditions of the Creative Commons Attribution license (http://creativecommons.org/licenses/by/3.0/). 